\title{
Spill Over Effects of Inpatient Bed Capacity on Accident and Emergency Performance in
}

England

\author{
R. Friebel \& R. Juarez
}

\begin{abstract}
The English National Health Service (NHS) has failed to meet the four-hour waiting time target to admit, transfer or discharge 95 per cent of patients attending Accident and Emergency Departments (A\&E) since 2013. A growing number of patients requiring inpatient care are waiting on trolleys longer than four hours before admission to a hospital bed. This study examines the role of bed occupancy in the deterioration of A\&E performance in the NHS. Longitudinal panel data methods are used to analyse hospital data ( $\mathrm{n}=72,129,886)$ for 143 Trusts from $1^{\text {st }}$ June 2016 to $31^{\text {st }}$ October 2019. The average bed occupancy rate across the study period was $93.2 \%$. A $1 \%$ increase in bed occupancy was associated with a 9.5 percentage point decrease in the Trusts' probability of meeting the waiting target, and an approximately 6 patient increase in four hours to 12 -hours trolley waits per 1,000 admissions. These relationships became more pronounced with rising bed occupancy levels above a $90 \%$ threshold. Bed occupancy is associated with significant negative spill-over effects on A\&E performance. We estimate a minimum investment in 3,861 additional inpatient beds across the NHS to improve A\&E performance in England. Relevant lessons can be derived for health care systems that have observed similar trends in increasing bed occupancy and deteriorations in A\&E performance, including Ireland, Canada and Israel.
\end{abstract}

Keywords: Performance Targets, Health Services Research, Bed Pressures, Quality of Care 


\section{INTRODUCTION}

Many health care systems experience long waiting times and overcrowding in Accident \& Emergency (A\&E) departments. [1, 2, 3] These can cause delays in access to medical treatments, carry risks to health outcomes $[4,5,6,7]$ and contribute to burn-out among hospital staff and low retention rates. [8] To address the problem of long waiting times in A\&E in the English National Health Service (NHS), the Labour government pledged to improve services such that by 2004 no patient would wait longer than four hours from arrival to admission, transfer or discharge. $[9,10]$ This target was reduced to $98 \%$ in 2004 to allow for clinical exceptions, [11] and further reduced to 95\% in 2010 due to concerns about its clinical justification. [12] Although A\&E waiting times and patient satisfaction improved initially during this period, [13,14] hospital performance has declined from $96.9 \%$ of patients seen on target in 2011-12, to $84.8 \%$ of patients in 2018-19. [15] The NHS as a whole has not met the four-hour target since 2013, with one in every six patients attending $A \& E$ now waiting over four hours from arrival. In spite of effective strategies to address the sustained pressures experienced by A\&E departments across the country, for instance by improving accessibility and availability of care in the community, recently the appropriateness of the four-hour target has been questioned by NHS leadership and Ministers, [16, 17] while professional bodies such as the Royal College of Emergency Medicine remain supportive of it.

Several factors contribute to deteriorating A\&E performance, including a rise in potentially avoidable attendances from patients unable to access services in the community, and increasing clinical complexity of those in need of emergency care. [18] A\&E performance is profoundly affected during winter months, [19] with patients that attend A\&E being sicker and more likely to require admission to hospital compared to other seasons, putting pressure on hospital capacity. [20] A common consequence of such demand shocks are trolley waits from patients waiting for an inpatient bed after a decision to admit has been made in A\&E, which parallels poor performance against the four-hour target. In 2018-19, 629,000 patients waited longer than four hours for admission (i.e., increased by $1.7 \%$ from the previous year). [21] Trolley waits are indicative of sub-standard care that results from hospitals' insufficient capacity to deal with patients in need of treatment as an inpatient, suggesting that demand for services exceeds available capacity. It is possible that constraints to inpatient capacity lead to negative spill-overs on A\&E performance, with the unintended consequence of reflecting poorly and unfairly on the quality of care provided by A\&E staff. [11] And indeed, due to strategies that encouraged the closure of hospital beds without achieving corresponding reductions in demand, [22] average national bed occupancy has risen above $92 \%$, [23] and some hospitals recurrently operate at maximum bed capacity. High bed occupancy also concerns health care systems of other countries, [24] for example Ireland, Canada and Israel report average bed occupancy rates above $90 \%$, while experiencing deteriorations in A\&E performance. [25]

Since 2011, resource-stretched hospitals in England received £3.1 billion in financial support to deal with poor hospital performance during winter periods. [26] Investments aimed to improve A\&E performance 
and increase hospital bed capacity, for instance through opening new wards and drawing in additional inpatient beds. Financial support was temporary and service provision commonly returned to pre-winter settings once funds were exhausted, without sustainable strategies to reduce bed occupancy in the long term. Hospital bed shortages are considered a key determinant of crowding, [27, 2] with studies demonstrating that high bed occupancy is associated with crowding [28] and extended waits in A\&E. [29] Several literature reviews consistently found A\&E crowding to be associated with poor patient outcomes, $[30,31,2,32]$ and poor hospital performance on process measures such as number of patients in the waiting room, $A \& E$ occupancy, time to treatment, and the number of $A \& E$ patients awaiting inpatient beds. [33, 34, 27, 2, 35] In the NHS, concerns about the implications of such high bed occupancy for the delivery of health services have been expressed by clinical leaders, [36] since bed occupancy above $90 \%$ was linked to inefficient inpatient care processes [37] and poorer inpatient outcomes. [38, 39, 40, 41] However, a recent study featuring the NHS found no clinically significant association between bed occupancy, discharge processes and hospital readmissions, [42] but it is possible that any negative effects may have been absorbed by services in the community.

As limited capacity is detrimental in facilitating patient flow into the hospital, we hypothesise that bed occupancy is an important determinant of A\&E performance. Using data on all NHS hospitals in England for every day over a three-year period, we examined the spill-over effects of bed occupancy on hospital ability to meet the four-hour target and to address trolley waits. The promise of an additional $f^{20.5}$ billion investment for the NHS until 2023/24 [43] by the newly elected Conservative government creates an opportunity to support hospitals in gaining the strength required to improve A\&E performance. While the NHS Long Term plan sets out a $£, 5$ billion earmarked spent to reduce waiting times and stabilise Trusts' finances between 2018/19 and 2023/24, [44] it remains unclear what proportion of funding should be spent on new hospital capacity versus other worthwhile investments in the health care system, such as strategies to reduce demand for hospital services. Modelling the direction and degree of this relationship permitted us to make predictions about the required investments in NHS bed stock to allow for improvements in A\&E performance.

\section{METHODS}

\section{Study sample}

We studied performance of hospital Trusts (i.e., some of which manage several hospital sites) in England between $1^{\text {st }}$ June 2016 to $31^{\text {st }}$ October 2019. A 41 months (i.e., 1248 days) study period was chosen based on the availability of data and relevance of this issue to policymakers, $[47,48]$ including to inform the ongoing clinical-led review on target use for performance measurement in England. [49] Data was provided following a Freedom of Information request submitted to NHS England and NHS Improvement (i.e., the non-departmental public body of the Department of Health and Social Care responsible for performance and regulation of the NHS) on $10^{\text {th }}$ October 2019. Data was received on $7^{\text {th }}$ 
November 2019, including information as reported by the Trust on bed availability (e.g., core beds and escalation beds) and occupancy levels, hospital demand (e.g., A\&E attendances and emergency admissions, subcategorised by $A \& E$ type), and performance (e.g., proportion of patients meeting the four hour waiting time target, number of patients waiting on trolleys for four hours to 12-hours, and those waiting for over 12-hours) for each day and Trust across the study period.

\section{Accident and Emergency performance}

According to the revised waiting standard introduced in 2010,95\% of all patients seeking care at any A\&E department in England should be admitted, transferred or discharged within four hours of arrival. Information on the number of patients achieving this target is collected daily by each Trust and submitted electronically to NHS England and NHS Improvement through an automated data-collection system. This system was introduced in 2017 to reduce the administrative burden of manual reporting. The collection of daily information of A\&E performance statistics started with the introduction of daily situation reports to monitor hospital performance during the winter period in 2012. [50] We calculated daily $A \& E$ performance as the proportion of total number of patients meeting the four-hour target out of all patients attending the $A \& E$ department on a given day. For patients whose $A \& E$ attendance spanned two calendar days (e.g., if the patient arrived at 10:00 pm and was admitted at 1 am the following day), the record was linked to the later day. This includes both information on attendance and breach of target.

NHS England and NHS Improvements classify trolley waits as operational issues and the collection of trolley wait data started in April 2017. Trolley waits describe patients who received a decision to admit, but who are not immediately provided an inpatient bed. Trolley waits are reported for patients waiting between four hours and 12-hours (i.e., 4:00 hours to 12:00 hours), and for patients waiting longer than 12hours (i.e., >12:01 hours). The waiting time is measured from the point of decision to admit, or when treatment in $A \& E$ is completed, to the actual time of admission. It applies to an emergency admission via A\&E defined as the time of patient departure to attend an operating theatre, an inpatient ward, or imaging or diagnostic service prior to admission to an inpatient bed. It also refers to the time of collection for transfer to another hospital. If additional treatment is required in the A\&E department of the receiving Trust, a new trolley waiting period starts at the time of treatment completion (i.e., between end of treatment and admission to an inpatient bed), levied against the receiving Trust's performance. We calculated trolley waits as the proportion of patients waiting between four hours and 12-hours, and longer than 12-hours, from the total number of emergency admissions via A\&E for each Trust and day across the study period. The crude number of trolley waits is expressed per 1,000 emergency admissions.

\section{Bed occupancy}

The collection of bed data (i.e., overnight beds and day beds) follows the central returns form KH03 that was introduced to NHS providers in 1987. [51] For each Trust, it identifies the total number of beds 
available for treatment of patients. It includes all core and escalation beds on the day of reporting, such as beds closed but occupied, and excludes beds that are closed but unoccupied. For example, when beds are closed due to infection control, only occupied beds are accounted. Moreover, the data excludes cots used by babies, and beds used by maternity services and mental health services. The number of available beds and the number of occupied beds is determined in a snapshot at $8 \mathrm{am}$ on a given day. We calculate bed occupancy as the ratio of number of beds occupied and number of bed stock available for each Trust and day across the study period. Compared with previous studies that relied on quarterly bed stock data, we were able to use a time varying denominator for a more accurate estimation of daily bed occupancy rates.

\section{Statistical analysis}

We first assessed the relationship between daily bed occupancy and the proportion of patients not admitted, transferred or discharged within four hours of attending A\&E, and then the number of patients waiting for an inpatient bed on trolleys between four hours and 12-hours, and longer than 12-hours. In each case, we used linear panel data models, which make use of the longitudinal nature of the data, [52] with observations across 143 Trusts and 1248 time points. The models used hospital-level fixed effects, which account for unobserved heterogeneity in Trust characteristics (i.e., such as teaching status, or characteristics of the surrounding area), assuming that they remained constant across the study period.

[53] We used standard errors clustered at Trust-level, because the correlation between errors for observation in the same Trust are likely to be greater than those from other Trusts. Our regression models adjusted for the number of A\&E attendances by two main A\&E types (i.e., type 1 and type 3 ) as most hospitals operate a major A\&E department (i.e., type 1) and a minor injury unit/walk-in centre.

Directing patients based on their severity could have potential pressure easing effects on A\&E departments and positively impact on hospital ability to meet performance targets. Moreover, we control for emergency admissions via other routes (i.e., total emergency admissions net of emergency admissions via $A \& E$ ) that include emergency admissions directly to the Trust upon request by a General Practitioner, as these admissions are independent of the action of A\&E departments. Our models also control for day of the week (i.e., entered dummy variables for each day of the week, using Monday as the reference case), [54] national holidays observed in England (i.e., bank holidays), common trends and seasonality through inclusion of separate year and month dummies, and the number of escalation beds as a proportion of total bed stock available in a given Trust and day. The proportion of escalation beds was included to examine the relationship between hospitals' decision to invest into temporary bed stock versus permanent capacity on outcomes.

We further estimated conditional logistic regression models to evaluate the probability for Trusts to meet the four-hour target based on a distribution of bed occupancy levels observed across the study period. We adjusted for the same confounders as described in the linear model and applied Trust-level fixed effects. 
To explore a potentially non-linear relationship between bed occupancy and A\&E performance that could result from flow problems triggered by high bed occupancy, we tested the hypothesis that higher levels of bed occupancy are associated with a reduced probability of meeting the four-hour target, and a greater number of patients waiting on trolleys. It was possible that the relationship becomes stronger once beds become scarce, since pressure on beds is increasingly unmanageable for hospital teams with spill-over effects on the care provided in A\&E departments. Therefore, as sensitivity analysis we test for non-linear associations between bed occupancy rates and A\&E performance by entering dummy variables for each bed occupancy threshold ranging from $100 \%$ to below $80 \%$, using $92 \%$ as reference case. We chose this threshold because the NHS Operational Planning and Contracting Guidance 2020/21 requires hospitals to reduce bed occupancy levels to a maximum of $92 \%$ through acute bed expansions, increasing community care, investment in primary care and improvements in length of stay and admission avoidance. [53] To visualise the non-linear relationship between bed occupancy and outcomes, we plotted the coefficients and associated confidence intervals for each bed occupancy threshold.

Some Trusts lacked complete data, leading to variation in the number of observations between different outcomes (i.e., proportion of patients missing the four-hour target ( $64 \%$ of maximum possible sample); number of patients on trolleys (4-hours to 12 -hours) (62\% of maximum possible sample); and number of patients on trolleys longer than 12 -hours ( $63 \%$ of maximum possible sample)), which we addressed by employing an unbalanced panel data model. To assess the impact of missing data, we constructed a strictly balanced panel as sensitivity analysis that was limited to 131 Trusts with complete data across 271 days. All analyses were performed in STATA SE 16.

\section{RESULTS}

\section{Study sample}

Between $1^{\text {st }}$ June 2016 and 31 ${ }^{\text {st }}$ October 2019, 72,129,886 patients attended A\&E departments across 143 NHS Trusts. The largest proportion of patients attended A\&E type 1 (70\% of patients were treated in major emergency facilities), followed by A\&E type 3 (27\% of patients were treated in a minor injury facility), and A\&E type 2 ( $3 \%$ of patients were treated in a consultant-led, single speciality facility). The total number of A\&E attendances increased from 23,362,301 in 2016-17 to 24,826,981 in 2018-2019. The largest proportion of patients attended A\&E on Mondays (15\%), with fewest attendances recorded on Saturdays (13\%). The mean attendance time across all A\&E departments was 2 hours 21 minutes (Standard Deviation (S.D.) = 59 minutes). [55] A total of 11,379,806 patients were admitted as an emergency inpatient across the study period (i.e., $15.8 \%$ of all A\&E attendances resulted in an emergency admission). 


\section{Trends in bed occupancy, four-hour waiting time performance and trolley waits}

We found a small decrease in mean bed occupancy rate from 93.6\% (S.D. $=5.8 \%$ ) per day and Trust in quarter (q) 2/2016-17, to $92.9 \%$ (S.D. $=5.2 \%$ ) in q2/2019-20. This trend deviates from official bed occupancy statistics, [23] because our data reports on the mean bed occupancy per day aggregated by quarter, whereas NHS England and NHS Improvement report a single snapshot of data at the end of each quarter. The mean number of patients missing the four-hour target per day and Trust increased from 43.2 (S.D. $=44.9$ patients) in q2/2016-17, to 71.9 (S.D. = 62.5 patients) in q2/2019-20. A total of 1,683,309 patients waited on trolleys between four hours and 12-hours, and a total of 9,127 patients waited on trolleys longer than 12-hours across the study period. The mean number of four hours to $12-$ hours trolley waits per 1,000 emergency admissions increased from 90.7 patients (S.D. $=122.1$ patients) per day and Trust in q1/2017-18, to 148.8 patients (S.D. = 160.3 patients) in q2/2019-20; and the mean number of >12-hours trolley waits per 1,000 emergency admissions increased from 0.2 patients per day and Trust in $\mathrm{q} 1 / 2017-18$ (S.D. $=1.3$ patients), to 3.1 patients (S.D. $=9.4$ patients) in $\mathrm{q} 2 / 2019-20$. Table 1 presents summary statistics on a quarterly basis.

$$
<<<\text { Table } 1 \text { here }>>
$$

\section{Panel data models}

Table 2 presents regression output from all linear panel data models with bed occupancy entered as a continuous variable and across a total of 132 Trusts (i.e., the number of Trusts with unique information on outcome measures). The number of observations per Trust varied by outcome measure. For example, an average of 882 daily observations (ranging from 290 observations to 942 observations) were analysed per Trust for the proportion of patients missing the four-hour target, 836 daily observations (ranging from 195 observations to 914 observations) per Trust for the number of patients on trolleys (4-hours to 12-hours), and 863 daily observations (ranging from 238 observations to 940 observations) per Trust for number of patients on trolleys longer than 12-hours. We find that for each one percent increase in bed occupancy, the proportion of patients in A\&E admitted, transferred or discharged within the four-hour target decreased by $0.332 \%$-point (95\% CI, $0.252 \%$-point - $0.413 \%$-point). This suggests that the absolute number of patients seen within four hours decreased with a rise in hospital beds occupied, but also the Trusts' probability of meeting the four-hour target decreased by $9.5 \%$-point (95\% CI, $-10.1 \%$ point - -9.0\%-point) (see Table 3).

Patients admitted as an emergency via A\&E on days with high bed occupancy rate were more likely to wait on trolleys before being admitted to an inpatient bed. Our estimates highlight that for each one percent increase in bed occupancy at Trust-level, the number of patients on trolleys for four hours to 12 hours per 1,000 admissions increased by 5.541 (95\% CI, $3.851-7.233)$. We found a small statistically 
significant association of 0.036 (95\% CI, $0.016-0.058)$ between bed occupancy rate and proportion of patients on trolleys for over 12-hours per 1,000 admissions.

$$
\begin{aligned}
& <<\text { Table } 2 \text { here }>>> \\
& <<<\text { Table } 3 \text { here }>>>
\end{aligned}
$$

The relationship between Trusts' ability to meet the four-hour target and bed occupancy increased with rising levels of bed occupancy (see Figure 1), though not monotonically. For the number of patients waiting on trolleys between four hours to 12 -hours per 1,000 admissions, the relationship with bed occupancy appears flat until it reaches a 90\% threshold and rises thereafter. Similarly, for the number of patients waiting on trolleys for over 12-hours per 1,000 admissions the relationship appears flat initially and rises sharply when bed occupancy reaches the level of $98 \%$. Regression output for the non-linear relationships is presented in Appendix A.

$$
<<<\text { Figure } 1>>>
$$

Our findings for the linear specification were robust to changes in panel structure (see Appendix B and Appendix C), yet the magnitudes of the percentile effects in the non-linearity analyses changed in some cases when using the balanced panel (see Appendix D), though trends amongst percentiles remained relatively similar.

\section{DISCUSSION}

A\&E performance against the four-hour target in the NHS has deteriorated from $97.6 \%$ of patients spending less than four hours in A\&E in 2008-09, to 77.2\% of patients in 2018-19. [55] This falls into a period of national bed occupancy exceeding a $92 \%$ threshold; and now for one in every ten emergency admissions to hospital, a patient is waiting on a trolley longer than four hours for admission to an inpatient bed (i.e., a total of 629,000 trolley waits per year). [21] We find that a one percent increase in bed occupancy was associated with a $9.5 \%$-point ( $95 \%$ CI, -10.1\%-point - -9.0 \%-point) decrease in the Trust's probability of meeting the four-hour target, a 5.541 (95\% CI, $3.851-7.233)$ patient increase in four hours to 12-hours trolley waits per 1,000 admissions, and a 0.036 (95\% CI, $0.016-0.058)$ patient increase in trolleys for over 12-hours per 1,000 admissions. The magnitude of our findings for meeting the four-hour target and four hours to 12-hours trolley waits appears clinically significant, suggesting negative spill-over effects of high bed occupancy on A\&E performance. Based on the non-linear relationship between bed occupancy and outcome measures, our results imply that avoiding any increases in bed occupancy is likely to improve adherence to waiting time targets and reductions in four-hours to 
12-hours trolley waits. However, long trolley waits can be reduced by preventing bed occupancy rates exceeding $98 \%$.

Since 2011, the NHS has provided over $£^{3.1}$ billion of financial support to Trusts for temporary investments in bed capacity to deal with additional demands during winter months. [26] Often this resulted in the opening of temporary wards or an increased use of escalation beds. However, these mitigations represent short-term solutions to structural issues around hospital bed management, and indeed, our results demonstrate that the larger the proportion of escalation beds from total bed stock in a given Trust and day, the worse their performance against the four-hour target and the more patients waited on trollies. Rather than funding temporary escalation beds, Trusts could benefit from investing in stable capacity to reduce bed occupancy to more manageable levels. In the context of inpatient demand studied from $1^{\text {st }}$ June 2016 to $31^{\text {st }}$ October 2019, we found no statistically significant relationship between bed occupancy rates and A\&E performance below a 90\% threshold. To reduce mean bed occupancy to this threshold, in practice, this would mean investing in a minimum 27 additional inpatient beds for an average hospital, or 3,861 inpatient beds across the NHS (i.e., overall estimate calculated based on a linear relationship between average bed occupancy and average bed stock, multiplied by 143 Trusts). This accounts for approximately three percent of the currently available number of overnight inpatient beds. However, it is possible that an even greater number of inpatient beds may be required to account for behavioural changes in staff, for example if admission thresholds reduce as a response to additional capacity, with care being shifted from ambulatory care in A\&E to an inpatient setting. Moreover, investments in stable bed capacity should feature alongside strategies that might help free up capacity on inpatient beds, for example by reducing length of stay and turnover intervals, increasing day-case activity, or capacity investments into primary care, community care and social care to reduce demand for hospital services. Such a multi-strategy approach could help avoid that additional inpatient beds will simply become fully occupied, presenting a more sustainable solution to improving A\&E performance and is likely to positively impact quality of care in other parts of the hospital system. Our findings align with previous research on negative implications of high bed occupancy rates above $90 \%$ for the efficient delivery of emergency care and patient safety [29]. These included effects on A\&E overcrowding, [56, 57] a decreased ability of clinical teams in A\&E departments to admit patients to specialist wards, [58, 59, 60] premature hospital discharges [60], and the spread of hospital acquired infections. [61, 39] Whilst relevant, these studies offer limited help to policymakers in reducing A\&E crowding as they do not estimate how much bed occupancy should be made available to reduce it. Our study focused on waiting times in A\&E and performance against the four-hour target, rather than on crowding itself. To the best of our knowledge, no other studies have attempted to estimate the investment in additional inpatient beds required to improve A\&E performance across the NHS. Moreover, our study supports the assertion that high bed occupancy restricts patient flow, and consequently a hospital's ability to absorb demand shocks. In absence of effective strategies to reduce demand on hospital services and inpatient beds, our study 
provides relevant lessons for health care systems that have observed similar trends in increasing bed occupancy and deteriorations in A\&E performance over time, including Ireland, Canada and Israel. Additional stable inpatient capacity in these health care systems may reduce bed occupancy to more manageable levels with positive effects on $A \& E$ performance and spill-overs on quality of care in other parts of the hospital system.

\section{Strengths and limitations}

Bed occupancy represents one aspect of pressure experienced by hospital staff and may vary throughout the day. We measured hospital bed occupancy for 143 Trusts using data on the number of available beds and number of occupied beds from a daily snapshot collected at $8 \mathrm{am}$. Unlike previous research that calculated bed occupancy based on the number of inpatients recorded at midnight as numerator, and number of hospital beds per quarter as denominator, [42] our estimates more accurately reflect hospital bed pressure on a given day, because we account for day-varying bed stock. Our calculation of bed occupancy also distinguished between beds closed but occupied and beds that are closed but unoccupied, for example from closures due to infection control. However, it is possible that we discount some withinday variation since hospitals might be able to draw in additional bed capacity to deal with sudden increases in demand at short notice, or reopen beds previously recorded as closed. The relevance of bed occupancy as an important aspect of hospital pressure has been recognised by NHS England and NHS Improvement, with the integration of snapshot data into the daily situation reports published for Winter months since 2012. [62] Provided adequate staffing levels, high bed occupancy encumbers the allocation of admitted patients to an inpatient bed, therefore resulting in negative spill-overs on trolley waits. We show that when bed occupancy is below $90 \%$, patient flow from A\&E into the hospital appears overall undisrupted and hospital teams are able to admit patients into inpatient beds without long delays.

A\&E performance was measured by the proportion of patients missing the four-hour target and trolley waits. Both measures reflect on the quality of care provided by the hospital, because long waiting times are linked to delays in access to medical treatments, a risk to health outcomes, and lower patient satisfaction. The four-hour target was introduced as a standard of care to reduce growing waiting times in the NHS, but its clinical appropriateness has been questioned over the years. Indeed, the selection of the $95 \%$ cut-off was based on the Coalition government's claim that $98 \%$ was not clinically justified [12], however the initial introduction of the four-hour target in 2004 resulted in improved A\&E performance. $[13,14]$ It remains unclear whether daily performance against the four-hour target without adjusting for patient case-mix reflects appropriately on the hospitals' performance, for example some hospitals might see a greater proportion of clinically complex patients with longer consultation times. Because of a lack of available information, we were not able to adjust our analysis for characteristics of attending patients, including age, diagnosis, complexity, or percentage of ambulance arrivals, which might lead to omitted variable bias if they appear correlated with A\&E waiting times. Patient-level data would also help assess 
whether all groups are equally affected by high bed occupancy rates and it may also help explain the nonmonotonicity observed between bed occupancy and outcome measures. Moreover, it is also possible that admission thresholds vary by clinician, and pressures to meet the four-hour target might lead to swayed decision-making with research showing that proximity to the four-hour target predicts the likelihood of an admission. [14] To overcome these concerns, a replacement of the four-hour target in favour of four new indicators has been proposed by the Review of NHS Access Standards. [63] This includes measures on the time to clinical assessment, time to emergency treatment for critically ill or injured patients, time in A\&E, and utilisation of same day emergency care. The new indicators aim to better reflect patient preferences and ensure prioritisation of sicker patients.

A consideration regarding the use of trolley waits is that they can be affected by the quality of services provided elsewhere in the system. Hospital staff working in A\&E may be unduly penalised, for instance when patients are remaining in hospital beds longer than clinically required because of inefficient discharge processes, or unavailable post-discharge care. [64] To account for some of the unobserved variation in Trust-level characteristics, we employed an unbalanced panel data model with Trust-level fixed effects, which assessed the association in day-varying changes in bed occupancy across the study period with coexisting changes in $A \& E$ performance within the same Trust. We therefore were able to adjust for time-invariant effects on outcomes, but we are not able to fully discount that pressures may be affected by time-varying factors that have been unaccounted for by our model. [65] Examples for timevarying factors include Trusts being placed under 'special measures' by regulators, restructuring of services to provide specialist critical services, [66] or temporarily downgrading A\&E, which have not been controlled.

\section{Conclusions and policy implications}

The reduction of available inpatient beds in English hospitals is associated with significant negative spillover effects on $A \& E$ performance, as indicated by the four-hour waiting target and trolley waits. It is likely that high bed occupancy restricts patient flow, and with that the ability to absorb demand shocks. Based on data from 143 Trusts in England for a period of 1248 days, our findings provide quantitative support for concerns previously stated by clinical leaders and align with studies reporting on the adverse effects of high bed occupancy on patient safety and quality of care. Against the common strategy to reduce inpatient capacity further in the NHS, our findings suggest an investment into an additional minimum 3,861 inpatient beds, which supports plans to maintain the 3,000 beds added to NHS hospitals from October 2019 to deal with this year's Winter pressures outlined in the NHS Improvement Operational Planning and Contracting Guidance 2020/21. [67] Additional stable capacity would reduce bed occupancy to more manageable levels with positive effects on A\&E performance and spill-overs on quality of care in other parts of the hospital system. 


\section{Funding}

This research did not receive any specific grant from funding agencies in the public, commercial, or notfor-profit sectors.

\section{Data sharing}

The data was obtained following a Freedom of Information Request to NHS England and NHS Improvement and will be made available upon request.

The lead author $(\mathrm{RF})$ affirms that the manuscript is an honest, accurate, and transparent account of the study being reported; that no important aspects of the study have been omitted; and that any discrepancies from the study as planned have been explained.

\section{REFERENCES}

[1] S. Di Somma, L. Paladino, L. Vaughan, I. Lalle, L. Magrini and M. Magnanti, "Overcrowding in emergency department: an international issue," Internal and Emergency Medicine, vol. 10, p. 171-175, 2015.

[2] N. R. Hoot and D. Aronsky, "Systematic Review of Emergency Department Crowding: Causes, Effects, and Solutions," Annals of Emergency Medicine, vol. 52, no. 2, pp. 126-136.e1, 2008.

[3] L. G. Stead, A. Jain and W. W. Decker, "Emergency department over-crowding: a global perspective," International Journal of Emergency Medicine, vol. 2, no. 3, p. 133-134, 2009.

[4] A. Guttmann, M. J. Schull, M. J. Vermeulen and T. A. Stukel, "Association between waiting times and short term mortality and hospital admission after departure from emergency department: population based cohort study from Ontario, Canada," British Medical Journal, vol. 342, p. d2983, 2011.

[5] T. S. and E. Rivers, "Emergency department overcrowding in the United States: an emerging threat to patient safety and public health," Emergency Medicine Journal, vol. 20, pp. 402-405, 2003.

[6] H. E. Depinet, S. B. Iyer, R. Hornung, N. L. Timm and T. L. Byczkowski, "The effect of emergency department crowding on reassessment of children with critically abnormal vital signs," Academic Emergnecy Medicine, vol. 21, no. 10, pp. 1116-11120, 2014.

[7] W. Bonadio, J. Brazg, N. Telt, M. Pe, F. Doss, L. Dancy and M. Alvarado, "Impact of In-Hospital Timing to Appendectomy on Perforation Rates in Children with Appendicitis," Journal of Emergency Medicine, vol. 49, no. 5, pp. 597-604, 2015.

[8] F. McDermid, J. Mannix and K. Peters, "Factors contributing to high turnover rates of emergency nurses: A review of the literature," Australian Critical Care, 2019. 
[9] L. Mayhew and D. Smith, "Using queuing theory to analyse the Government's 4-h completion time target in Accident and Emergency departments.," Health Care Management Science, vol. 11, no. 1, pp. 11-21, 2008.

[10] Department of Health, "The NHS Plan: a plan for reform, a plan for investment," July 2000. [Online]. Available: https://webarchive.nationalarchives.gov.uk/20121102184216/http://www.dh.gov.uk/en/Publica tionsandstatistics/Publications/PublicationsPolicyAndGuidance/DH_4002960. [Accessed 19 February 2020].

[11] The Royal College of Emergency Medicine, "Emergency Medicine Briefing: Making the Case for the Four-Hour Standard," September 2018. [Online]. Available: https://www.rcem.ac.uk/docs/Policy/Making\%20the\%20Case\%20for\%20the\%20Four\%20Hou r\%20Standard.pdf. [Accessed 16 February 2020].

[12] P. Guven-Uslu, "Waiting time targets and informal professional networks in the English NHS," Qualitative Research in Accounting and Management, vol. 14, no. 3, pp. 307-327, 2017.

[13] S. Kelman and J. N. Friedman, "Performance Improvement and Performance Dysfunction: An Empirical Examination of Distortionary Impacts of the Emergency Room Wait-Time Target in the English National Health Service," Joumal of Public Administration Research and Theory, vol. 19, no. 4, p. 917-946, 2009.

[14] S. Mason, E. J. Weber, J. Coster, J. Freeman and T. Locker, "Time Patients Spend in the Emergency Department: England's 4-Hour Rule-A Case of Hitting the Target but Missing the Point?," Annals of Emergency Medicine, vol. 59, no. 5, pp. 341-349, 2012.

[15] NHS England, "A\&E Attendances and Emergency Admissions," NHS England, [Online]. Available: https://www.england.nhs.uk/statistics/statistical-work-areas/ae-waiting-times-andactivity/. [Accessed 12 February 2020].

[16] G. Iacobucci, "A\&E doctors urge NHS not to abandon four hour target," British Medical Journal, 2019.

[17] J. Illman, "A\&E medics tell Hancock: No evidence yet for replacing four-hour target," Health Services Journal, 15 January 2019. [Online]. Available: https://www.hsj.co.uk/quality-andperformance/aande-medics-tell-hancock-no-evidence-yet-for-replacing-four-hourtarget/7026703.article. [Accessed 16 February 2020].

[18] A. Steventon, S. Deeny, R. Friebel and T. Gardner, "Briefing: Emergency hospital admissions in England: which may be avoidable and how?," The Health Foundation, London, 2018.

[19] British Medical Association, "NHS Pressures - Winter 2018/19," British Medical Association, London, 2019. 
[20] E. Fisher and H. Smith, "Winter pressures: what's going on behind the scenes?," 11 February 2016. [Online]. Available: https://www.nuffieldtrust.org.uk/research/winter-pressures-what-sgoing-on-behind-the-scenes. [Accessed 9 March 2020].

[21] C. Baker, "NHS Key Statistics: England," 16 October 2019. [Online]. Available: https://researchbriefings.parliament.uk/ResearchBriefing/Summary/CBP-7281. [Accessed 12 February 2020].

[22] C. Imison, N. Curry, H. Holder, S. Castle-Clarke, D. Nimmons, J. Appleby, R. Thorlby and S. Lombardo, "Shifting the Balance of Care: Great Expectations," Nuffield Trust, London, 2017.

[23] NHS England, "Bed Availability and Occupancy Data - Overnight," NHS England, [Online]. Available: https://www.england.nhs.uk/statistics/statistical-work-areas/bed-availability-andoccupancy/bed-data-overnight/. [Accessed 12 February 2020].

[24] World Health Organization, "Bed occupancy rate (\%), acute care hospitals only," European Health Information Gateway, 17 October 2019. [Online]. Available: https://gateway.euro.who.int/en/indicators/hfa_542-6210-bed-occupancy-rate-acute-carehospitals-only/. [Accessed 16 February 2020].

[25] A. Björnberg, "Euro Health Consumer Index 2016 Report," Health Consumer Powerhouse, Marseillan, 2017.

[26] S. Anandaciva, "A short history of NHS winter funding," Kings Fund, 11 October 2018. [Online]. Available: https://www.kingsfund.org.uk/blog/2018/10/short-history-nhs-winter-funding. [Accessed 16 February 2020].

[27] British Medical Association, "State of the health system beds in the NHS: UK," British Medical Association, London, 2017.

[28] B. Jane E., T. Murrells, A. M. R. Morrow, Elizabeth and P. Griffiths, "CCare left undone' during nursing shifts: associations with workload and perceived quality of care," British Medical Journal Quality and Safety, vol. 23, pp. 116-125, 2014.

[29] J. S. Weissman, J. M. Rothschild, E. Bendavid, P. Sprivulis, E. F. Cook, R. S. Evans, Y. Kaganova, M. Bender, J. David-Kasdan, P. Haug, J. Lloyd, M. H. J. Selbovitz and D. W. Bates, "Hospital Workload and Adverse Events," Medical Care , vol. 45, no. 5, pp. 448-455 , 2007.

[30] J. B. Cunningham, W. G. Kernohan and T. Rush, "Bed occupancy, turnover intervals and MRSA rates in English hospitals.," British Journal of Nursing, vol. 15, no. 12, pp. 656-660, 2006.

[31] V. Vella, P. P. Aylin, L. Moore and A. King, "Bed utilisation and increased risk of Clostridium difficile infections in acute hospitals in England in 2013/2014," British Medicial Journal Quality and Safety, vol. 26, pp. 460-465, 2016.

[32] M. C. Blom, K. Erwander, L. Gustafsson, M. Landin-Olsson, F. Jonsson and K. Ivarsson, "The probability of readmission within 30 days of hospital discharge is positively associated with 
inpatient bed occupancy at discharge - a retrospective cohort study," BMC Emergency Medicine, vol. 15, no. 37, 2015.

[33] R. Friebel, R. Fisher, S. R. G. Deeny, Tim, A. Molloy and A. Steventon, "The implications of high bed occupancy rates on readmission rates in England: A longitudinal study.," Health Policy, vol. 123, no. 8, pp. 765-772, 2019.

[34] Department of Health and Social Care, "Press release: Prime Minister sets out 5-year NHS funding plan," Department of Health and Social Care, 18 June 2018. [Online]. Available: https://www.gov.uk/government/news/prime-minister-sets-out-5-year-nhs-funding-plan. [Accessed 16 February 2020].

[35] A. Charlesworth, B. Gershlick, Z. Firth, J. Kraindler and T. Watt, "Investing in The NHS Long Term Plan: Job Done?," The Health Foundation, June 2019. [Online]. Available: https://reader.health.org.uk/investing-in-the-NHS-long-term-plan/the-long-term-plansettlement\#workforce. [Accessed 9 March 2020].

[36] The Royal College of Surgeons of England, "NHS bed occupancy rates now at worst ever, new figures show," The Royal College of Surgeons of England , 24 May 2018. [Online]. Available: https://www.rcseng.ac.uk/news-and-events/media-centre/press-releases/nhs-bed-occupancyrates/. [Accessed 16 February 2020].

[37] The King's Fund, "The King's Fund calls for a review of hospital bed numbers," The King's Fund, 9 January 2020. [Online]. Available: https://www.kingsfund.org.uk/press/pressreleases/winter-pressure-hospital-bed-numbers. [Accessed 16 February 2020].

[38] NHS England, "Clinically-led Review of NHS Access Standards," NHS England, 2019.

[39] NHS Improvement, "Process and definitions for the daily situation report web form," NHS Improvement, 2018.

[40] Department of Health, "KH03 Quarterly Bed Availability and Occupancy," Department of Health, 2010.

[41] C. Hsiao, "Panel data analysis—advantages and challenges," TEST, vol. 16, pp. 1-22, 2007.

[42] NHS Digital, "Publication: Hospital Accident \& Emergency Activity 2018-19," NHS Digital, 12 September 2019. [Online]. Available: https://digital.nhs.uk/data-andinformation/publications/statistical/hospital-accident--emergency-activity/2018-19. [Accessed 16 February 2020].

[43] A. Bagust, M. Place and J. Posnett, "Dynamics of bed use in accommodating emergency admissions: Stochastic simulation model," British Medical Journal Vol. 319, No. 7203 , pp. 155-158, 1999.

[44] R. Jones, "Volatility in bed occupancy for emergency admissions," British Journal of Healthcare Management, vol. 17, no. 9, pp. 424-430, 2011. 
[45] W. Rashwan, W. Abo-Hamad and A. Arisha, "A system dynamics view of the acute bed blockage problem in the Irish healthcare system," European Journal of Operational Research, vol. 247, no. 1, pp. 276-293, 2015.

[46] S. Allder, K. Silvester and P. Walley, "Managing capacity and demand across the patient journey," Clinical Medicine, vol. 10, no. 1, pp. 13-15, 2010.

[47] M. Blom, F. Jonsson, M. Landin-Olsson and K. Ivarsson, " The probability of patients being admitted from the emergency department is negatively correlated to in-hospital bed occupancy - a registry study," International Journal of Emergency Medicine, vol. 7, no. 8, 2014.

[48] D. Darehed, B. S. B. Norrving and K. \&. B. M. Zingmark, "Patients with acute stroke are less likely to be admitted directly to a stroke unit when hospital beds are scarce: A Swedish multicenter register study.," European Stroke Journal, vol. 2, no. 2, p. 178-186, 2017.

[49] M. A. Borg, "Bed occupancy and overcrowding as determinant factors in the incidence of MRSA infections within general ward settings," Journal of Hospital Infection, vol. 54, no. 4, pp. 316-318., 2003.

[50] NHS England \& NHS Improvement, "Winter Daily SitRep 2012-2013 Data," NHS England and NHS Improvement, 2012.

[51] NHS England, "Clinically-led Review of NHS Access Standards, Interim Report from the NHS National Medical Director," March 2019. [Online]. Available: https://www.england.nhs.uk/wpcontent/uploads/2019/03/CRS-Interim-Report.pdf. [Accessed 16 February 2020].

[52] J. Gaughan, H. Gravelle and L. Siciliani, "Testing the Bed," Health Economics, vol. 24, no. 1, pp. $32-$ 44, 2015.

[53] U.S. Department of Health and Human Services, "Quick Guide for Clinicians Based on TIP 47 Substance Abuse: Clinical Issues in Intensive Outpatient Treatment," 2006. [Online]. Available: https://www.cecentral.com/assets/6794/Quick\%20Guide\%20for\%20Clinicians\%20Substance \% 20Abuse\%20Intensive\%20Outpatient\%20Treatment.pdf. [Accessed 16 February 2020].

[54] NHS England and NHS Improvement, "NHS Operational Planning and Contracting Guidance 2020/2021," NHS England and NHS Improvement, January 2020. [Online]. Available: https://www.england.nhs.uk/wp-content/uploads/2020/01/2020-21-NHS-OperationalPlanning-Contracting-Guidance.pdf. [Accessed 13 February 2020].

[55] L. A. Aday, "Establishment of a conceptual base for health services research," Journal of Health Services Research and Policy, vol. 6, no. 3, pp. 183-185, 2001.

[56] J. Bancroft and K. Saha, "Observing the NHS’s A\&E performance objectives: Is lean the cure?," International Journal of Quality \& Reliability Management, vol. 33, no. 8, pp. 1099-1123, 2016.

[57] G. Bevan and C. Hood, "What's measured is what matters: targets and gaming in the English public health care system.," Public Administration, vol. 84, no. 3, pp. 517-538, 2006. 
[58] D. Campbell, "Hospitals are facing 'unceasing demand' for A\&E and other services.," The Guardian., 19 September 2014. [Online]. Available:

www.theguardian.com/society/2014/sep/19/nhs-hospitalswaiting-time-demand-monitor .

[Accessed 14 January 2020].

[59] D. Campbell and R. Mason, "Plan to scrap A\&E target sparks furious backlash from medics," The Guardian, 15 January 2020. [Online]. Available:

https://www.theguardian.com/society/2020/jan/15/plan-to-scrap-ae-target-sparks-furiousbacklash-from-medics . [Accessed 16 January 2020].

[60] G. E. Day and L. South, "Improving the Health System with Performance Reporting - Real Gains or Unnecessary Work?," Asia Pacific Journal of Health Management, vol. 11, no. 1, pp. 8-14, 2016.

[61] G. Iacobucci, "A\&E performing better than last year but missed targets an ongoing concern, say medical leaders," British Medical Journal, vol. 364, p. 184, 2019.

[62] G. Iacobucci, " NHS is facing one its "bleakest" winters after worst ever performance on key targets," British Medical Journal, vol. 367, no. 16551, 2019.

[63] M. U. Majeed, D. T. Williams, R. Pollock, F. Amir, M. Liam, K. S. Foong and C. J. Whitaker, "Delay in discharge and its impact on unnecessary hospital bed occupancy.," BMC Health Services Research, vol. 12, no. 1, p. 410, 2012.

[64] R. Mason, "Matt Hancock signals A\&E waiting targets likely to be scrapped," The Guardian, 15 January 2019. [Online]. Available: https://www.theguardian.com/society/2020/jan/15/matthancock-accident-emergency-nhs-waiting-targets-likely-scrapped . [Accessed 16 January 2020].

[65] P. Smith, E. Mossialos and I. Papanicolas, "Performance Measurement for Health System Improvement: Experiences, Challenges and Prospects.," in World Health Organization European Ministerial Conference on Health Systems: Health Systems. Health and Wealth, Tallin, 2008.

[66] R. Friebel, K. Hauck and P. Aylin, "Centralisation of acute stroke services in London: Impact evaluation using two treatment groups" Health Economics, vol. 27, no. 4, 2018.

[67] M. Nagendran, G. Kiew, R. Raine and R. Atun, "Financial performance of English NHS trusts and variation in clinical outcomes: a longitudinal observational study," BMJ Open, vol. 9, 2018.

[68] R. Mannion and J. Braithwaite, "Unintended consequences of performance measurement in healthcare: 20 salutary lessons from the English National Health Service," Internal Medicine Journal, vol. 42, no. 5, pp. 569-574, 2012.

[69] Nuffield Trust, "A\&E waiting times," Nuffield Trust, 26 April 2019. [Online]. Available: https://www.nuffieldtrust.org.uk/resource/a-e-waiting-times. [Accessed 12 February 2020]. 